\title{
DEPRESSÃO E DISBIOSE: Estudo de Revisão Integrativa
}

\author{
DEPRESSION AND DISBIOSIS: Integrative Review Study \\ DEPRESIÓN Y DISBIOSIS: Estudio de Revisión Integrativa
}

\author{
Flávia Renata de Sousa Saraiva1*, \\ Luiza Marly Freitas de Carvalho', \\ Liejy Agnes dos Santos Raposo Landim ${ }^{1}$
}

\begin{abstract}
RESUMO
Objetivo: Realizar uma revisão Integrativa sobre disbiose e presença de transtorno depressivo. E mais especificadamente investigar os fatores que determinam a ingestão alimentar em portadores de depressão. Métodos: Consistiu em um estudo descritivo, retrospectivo com abordagem quantitativa. Para a seleção de amostras os artigos indexados de 2014 a 2019, em periódicos nacionais e internacionais, disponibilizados na íntegra (texto completo) em língua portuguesa, inglesa e que respondam a temática do estudo. A coleta de dados foi realizada nas bases Biblioteca Virtual de Saúde, LILACS, SCIELO, PubMed, e GOOGLE acadêmico dentre outros que contribuíram com informações significantes a este estudo, utilizando os seguintes descritores: Disbiose; Depressão; Consumo Alimentar. Resultados: Após utilização dos critérios de inclusão, exclusão, restaram 13 artigos para análise, interpretação e discussão. Observou-se que o profissional de nutrição têm o papel fundamental de como relacionar a disbiose e a depressão. E tratar o paciente atráves de uma alimentação equilibrada para o tratamento quanto da disbiose quanto da depressão. Considerações finais: Observou-se que o profissional de nutrição tem o papel fundamental para verificar se há de fato relação entre hábitos alimentares com a disbiose e a depressão e investigar de que forma a alteração na microbiota pode interferir no desenvolvimento.
\end{abstract}

Palavras-chave: Consumo Alimentar,Depressão, Disbiose.

\section{ABSTRACT}

Objective: To performan integrative review on dysbiosis and presence of depressive disorder. And more specifically investigate the factors that determine food in take in patients with depression. Methods: It consisted of a descriptive, retrospective study with a quantitative approach. For the selection of samples the articles indexed from 2014 to 2019, in national and international journals, made available in full (complete text) in Portuguese, English and that respond to the theme of the study. Data collection wasper formed in the Data bases Virtual health library, LILACS, SCIELO, Pub Med, and GOOGLE scholar am on go thers who contributed with significant information to this study, using the following descriptors: dysbiosis; Depression: Food consumption. Results: After using the inclusion criteria, exclusion, 13 articles wereleft for analysis, interpretation and discussion. It was observed that the nutrition Professional has the fundamental role of how to relate dysbiosis and depression. And treat the patient through a balanced diet for treatment as well as dysbiosis and depression. Final considerations: It was observed that the nutrition professional has the fundamental role in verifying whe ther thereis a relation ship between eat inghabits with dysbiosis and depression and investigating how the alteration in the microbiota can interfere in Development.

Key words: Food Consumption, Dysbiosis, Depression ${ }^{1}$

'Centro Universitário Santo Agostinho (UNIFSA), Teresina-PI. *E-mail: renatasaraiva22@hotmail.com 


\section{RESUMEN}

Objetivo: Realizar una revisión integradora sobre ladisbiosis y la presencia de trastornodepresivo. Y más específicamente investigar losfactores que determinanla ingesta de alimentos en pacientes condepresión. Métodos: Consistíaenunestudiodescriptivo y retrospectivo conun enfoque cuantitativo. Para laselección de muestraslos artículos indexados de 2014 a 2019, en revistas nacionales e internacionales, se ponen a disposiciónensutotalidad (texto completo) enportugués, inglés y que responden al tema delestudio. La recopilación de datos se realizóenla biblioteca de salud virtual de bases de datos, LILACS, SCIELO, PubMed y el académico de GOOGLE, entre otros, que contribuyeronconinformación significativa a este estudio, utilizando lossiguientesdescriptores: disbiosis; Depresión; Consumo de alimentos. Resultados: Después de utilizar loscriterios de inclusión, exclusión, 13 artículos fuerondejados para suanálisis, interpretación y discusión. Se observó que elprofesional de lanutricióntieneel papel fundamental de cómo relacionar ladisbiosis y ladepresión. Y tratar al paciente a través de una dieta equilibrada para eltratamiento, así como ladisbiosis y ladepresión. Consideracionesfinales: Se observó que elprofesional de lanutricióntieneel papel fundamental enlaverificación de si existe una relación entre los hábitos alimenticiosconladisbiosis y ladepresión e investigar cómolaalteraciónenla microbiota puede interferir enDesarrollo.

Palabras clave: ingesta de alimentos, depresión, disbiosis.

\section{INTRODUÇÃO}

A depressão é uma doença mental caracterizada por um comprometimento do estado físico e psicológico do indivíduo. Seus principais sintomas são: tristeza persistente, falta de energia, irritabilidade, ansiedade, perda de interesse por atividades que normalmente geravam prazer, baixa autoestima, alteração do sono e do apetite. O sentimento de tristeza é natural em momentos adversos da vida, portanto, para ser dado o diagnóstico de depressão, os sintomas descritos acima devem estar presentes em sua maioria e ter uma duração mínima de duas semanas (SEZINI e GIL, 2014).

A Depressão atualmente é vista como a quarta doença mais presente no mundo. Estima-se que a doença afete 121 milhões de pessoas, e menos de $25 \%$ dos deprimidos tem acesso ao tratamento. Calcula-se que 5 a $10 \%$ da população mundial sofrerão ao menos um episódio de depressão ao longo da vida. As mulheres apresentam chances maiores de deprimir (10 a $20 \%$ ) do que os homens (5 a $12 \%$ ) (BARBOSA et al., 2014).

De acordo com a Organização Mundial de Saúde a depressão caracteriza-se por episódio depressivo de no mínimo de duas semanas durante as quais há um humor 
deprimido ou perda de interesse pelas atividades cotidianas. Além de alterações no apetite ou peso, sono e atividade psicomotora; diminuição da energia; sentimentos de desvalia ou culpa; dificuldades para pensar, concentrar-se ou tomar decisões; pensamentos recorrentes sobre morte ou ideação suicida, planos ou tentativas de suicídio (PEREIRA et al., 2018).

A disbiose intestinal se caracteriza por alterações na atividade e local de distribuição da microbiota intestinal, em que ocorre predomínio das bactérias patogênicas sobre as benéficas. Esse desequilíbrio reflete no aumento da permeabilidade do intestino e na diminuição da seletividade na absorção de toxinas, bactérias, proteínas ou peptídeos, assim, contribuindo para inflamação local e sistêmica. Entre as causas da disbiose, destacam-se o estresse psicológico e fisiológico, a idade e alimentação. Esse distúrbio, cada vez mais comum, vem sendo considerado como relevante no diagnóstico de várias desordens, tais como transtornos de humor, que inclui a depressão (DASH et al, 2015).

Atualmente, existe uma corrente de investigação que tem como hipótese de trabalho o contributo da disbiose entérica para a inflamação $\mathrm{Gl}$ e a influência desta no eixo cérebro-intestino. Há evidência de que qualquer perturbação no equilíbrio deste eixo produz alterações na resposta desencadeada face ao estresse e no comportamento em geral (SILVESTRE, 2015).

Após a globalização e o grande crescimento dos fast-food na sociedade moderna, a alimentação equilibrada e saudável se tornou cada vez mais difícil de ser realizada. Portanto, sabe-se que a alimentação equilibrada é determinante na manutenção da saúde, melhor qualidade de vida, sem afetar o estado de humor e bem-estar do indivíduo (NORMAM et al., 2015).

Sendo que, uma alimentação desregrada, com alto consumo de alimentos industrializados e exposição a toxinas que não podem ser digeridas pelo organismo pode levar a uma desordem na função intestinal, resultando assim em uma disbiose. Frente a esse contexto, surgiu o seguinte questionamento: como a presença de disbiose no indivíduo pode levar ao quadro de depressão? Assim o objetivo geral desse estudo é realizar uma revisão Integrativa sobre disbiose e presença de transtorno depressivo. E mais especificadamente investigar os fatores que determinam a ingestão alimentar em portadores de depressão. 


\section{MÉTODOS}

Estudo de revisão integrativa da literatura, de natureza qualitativa e exploratória, com abordagem teórica. A referida pesquisa traz como benefícios informações relevante a relação entre disbiose e depressão e contribuindo para a identificação dos fatores que estão relacionados com distúrbio mental além de incentivar aos leitores a importância do cuidado em relação aos hábitos alimentares saudáveis. Além de aumentar o número de trabalhos publicados sobre a mesma temática. Esse processo permite o aprofundamento do conhecimento sobre a temática, além de apontar lacunas que precisam ser preenchidas por novos estudos.

A busca dos artigos foi realizada em cinco bases de dados eletrônicos acessados na Biblioteca Virtual em Saúde (BVS): Medical LiteratureAnalysisandRetrieval System on-line (MEDLINE), Literatura Latino-Americana e do Caribe em Ciências da Saúde (LILACS), ScientificElectronic Library Online (SciELO), National Library of Medicine(PubMED) e o GOOGLE ACADÊMICO.

Para o levantamento dos estudos foram utilizados os descritores: "disbiose", "depressão", "adulto" e "consumo alimentar", no idioma português cadastrados nos Descritores em Ciências da Saúde (DeCS) e inglês, de acordo com o Medical SubjectHeadings (MeSH) "depression", "dysbiosis", e "foodconsumption" adaptados de acordo com a base de dados utilizada.

Três etapas foram seguidas no desenvolvimento do estudo: a primeira busca foi iniciada pelos descritores: "relação depressão" e "disbiose", utilizando o operador booleano AND; segundo com os descritores " depressão" e " consumo alimentar " conectados pelo operador booleano AND; e por último, "disbiose" e "consumo alimentar ". A busca foi realizada no mês de março de 2019, foram selecionados inicialmente 23 artigos que abordavam os descritores, que após análise do objeto de estudo e os critérios de inclusão, restaram 13 artigos, conforme Figura 1. 
Figura 1: Fluxograma do processo de busca e seleção dos estudos inclusos na revisão. Teresina (PI), Brasil, 2019.

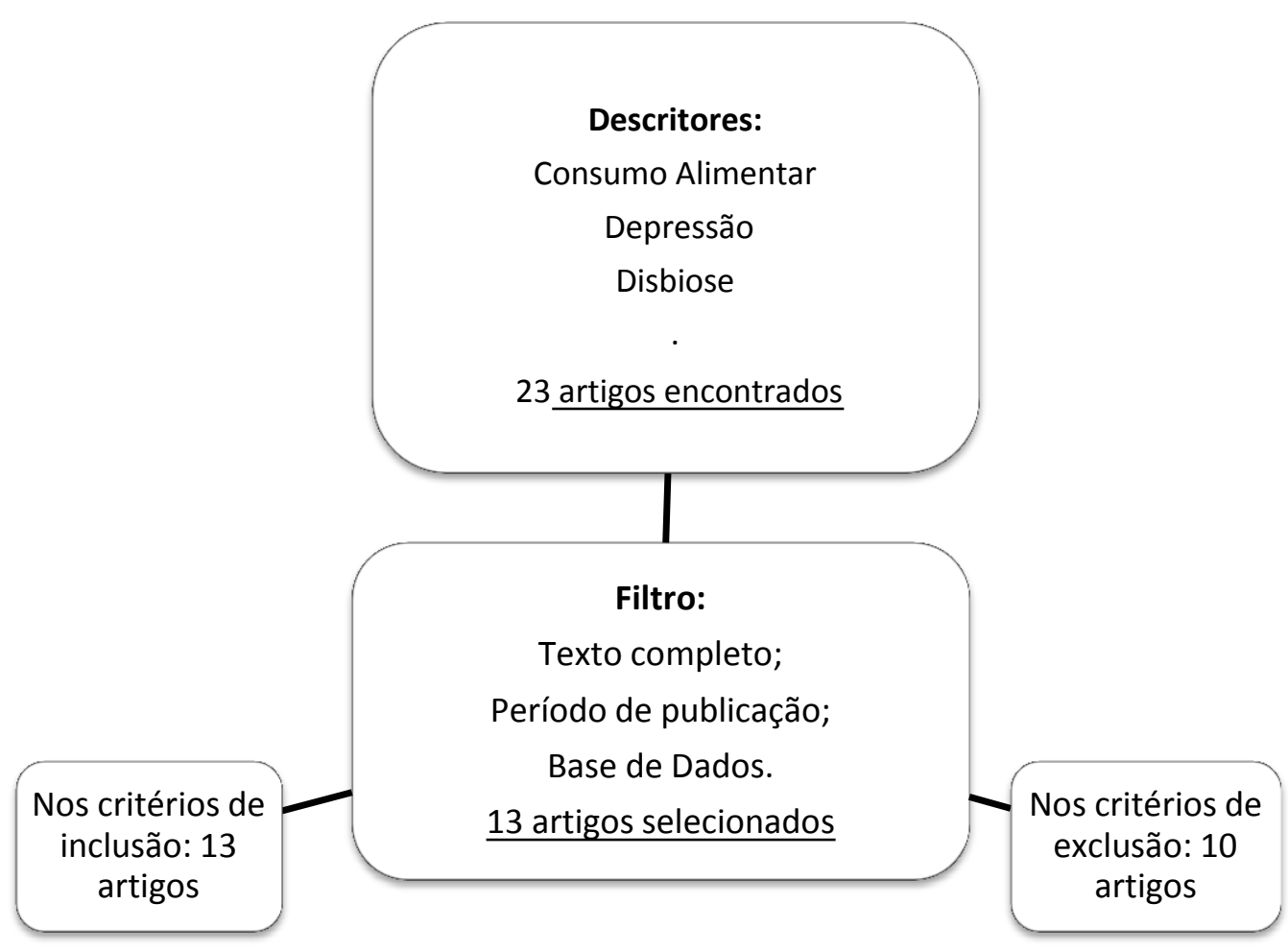

Fonte: Biblioteca Virtual de Saúde (2019).

Para selecionar a amostra, foram utilizados os seguintes critérios de inclusão: ser artigo original, indexado nas bases de dados selecionadas, nos idiomas: português e inglês; publicado entre os anos de 2014 e 2019. A escolha desse período atendeu ao critério de temporalidade, em que se considerou o recorte de cinco anos, por se tratar de publicações mais atuais. Os critérios de exclusão foram publicações de tese, dissertação, monografia e artigos que não tinham aderência à temática.

Foi aplicada a técnica de análise de conteúdo temática, constituída de duas etapas: pré-análise e análise. Na primeira etapa foi efetuada a leitura flutuante dos textos, que possibilitou a constituição do corpus; seguiu-se com leitura exaustiva desses que, agrupados por similaridade, constituíram as categorias de análise, conforme a compreensão e transversalização do discorrido pelos autores. 


\section{RESULTADOS}

Na Tabela 1 encontra-se a distribuição das produções científicas segundo o período de publicação e o total de artigos.

Tabela 1: Distribuição dos resultados referentes as produção científicas utilizadas na RI por período de publicação.

\begin{tabular}{ccc}
\hline Período & N & $\%$ \\
\hline $2014-2015$ & 3 & $23,1 \%$ \\
$2016-2017$ & 6 & $46,1 \%$ \\
$2018-2019$ & 4 & $30,8 \%$ \\
\hline Total & 13 & 100,0 \\
\hline
\end{tabular}

Fonte: Dados da pesquisa, 2019.

Observa-se a predominância das publicações entre os anos de 2016 e 2017 (46,1\%) 2018 e 2019 (30,8\%), e as publicações foram encontradas em maior quantidade nas bases de dadosPUBMED(53,8\%),GOOGLE ACADÊMICO(30,8\%), SCIELO $(7,7 \%)$ e LILACS $(7,7 \%)$.

Tabela 2: Análise das bases de dados e os idiomas.

\begin{tabular}{ccc}
\hline Base de Dados & N & $\%$ \\
\hline Google acadêmico & 4 & 30,8 \\
Pubmed & 7 & 53,8 \\
Scielo & 1 & 7,7 \\
Lilacs & 1 & 7,7 \\
Total & 13 & 100,0 \\
\hline Idiomas & $\mathrm{N}$ & $\%$ \\
\hline Português & 6 & 46,2 \\
Inglês & 7 & 53,8 \\
Total & 13 & 100,0 \\
\hline
\end{tabular}

Fonte: Dados da pesquisa, 2019.

$\mathrm{Na}$ tabela 3 pode-se observar a distribuição dos artigos conforme o ano, foco/objetivo principal e tipo de estudo. 
Tabela 3: Distribuição das produções científica publicada no período de 2014 a 2019 segundo o ano, foco principal e o tipo de estudo.

\begin{tabular}{|c|c|c|c|c|}
\hline $\begin{array}{c}\text { Autor/ } \\
\text { ano }\end{array}$ & Título & Objetivo & Metodologia & Resultados \\
\hline $\begin{array}{l}\text { SEZINI et } \\
\text { al,2014 }\end{array}$ & Nutrientes e Depressão & $\begin{array}{l}\text { Analisar o papel que determinados } \\
\text { nutrientes exercem na etiologia e } \\
\text { tratamento da doença depressiva. }\end{array}$ & $\begin{array}{l}\text { Revisão } \\
\text { Bibliográfica }\end{array}$ & $\begin{array}{l}\text { As pesquisas evidenciam que a nutrição tem um papel } \\
\text { fundamental tanto na prevenção da doença, como na } \\
\text { recuperação de pacientes depressivos. }\end{array}$ \\
\hline $\begin{array}{l}\text { VEDOVATO et } \\
\text { al., } 2014\end{array}$ & $\begin{array}{l}\text { O eixo intestino-cérebro } \\
\text { e o papel da serotonina. }\end{array}$ & $\begin{array}{l}\text { Buscar informações na literatura } \\
\text { que descrevam a interação } \\
\text { intestino-cérebro e o papel da } \\
\text { serotonina nessa interação. }\end{array}$ & $\begin{array}{l}\text { Revisão } \\
\text { Bibliográfica }\end{array}$ & $\begin{array}{l}\text { Os estudos evidenciaram que há uma relação direta } \\
\text { entre as reações ocorridas no eixo intestino-cérebro, } \\
\text { que influenciam episódios de depressão. }\end{array}$ \\
\hline $\begin{array}{l}\text { RODRIGUES, } \\
2015\end{array}$ & $\begin{array}{l}\text { Possível relação entre } \\
\text { microbioma intestinal e } \\
\text { depressão em } \\
\text { humanos: Uma revisão } \\
\text { de literatura. }\end{array}$ & $\begin{array}{l}\text { Investigar de que forma a alteração } \\
\text { da microbiota intestinal pode } \\
\text { interferir nos quadros de } \\
\text { alterações do humor e no } \\
\text { desenvolvimento de depressão. }\end{array}$ & $\begin{array}{l}\text { Revisão de } \\
\text { Literatura }\end{array}$ & $\begin{array}{l}\text { A relação existente entre o intestino e o cérebro, } \\
\text { desencadeiam sintomas da disbiose, e de quadros de } \\
\text { depressão, assim a ingestão de alimentos nutricionais } \\
\text { melhoram a disbiose e a depressão. }\end{array}$ \\
\hline $\begin{array}{l}\text { SOZA; } \\
\text { BRETENGANI } \\
2016\end{array}$ & $\begin{array}{l}\text { The } \\
\text { influenceofalimentation } \\
\text { aboutthe intestinal } \\
\text { microbiota } \\
\text { andimmunity }\end{array}$ & $\begin{array}{l}\text { Demonstrar a importância da } \\
\text { microbiota intestinal para o ser } \\
\text { humano. }\end{array}$ & $\begin{array}{l}\text { Revisão } \\
\text { Bibliográfica, } \\
\text { exploratória }\end{array}$ & $\begin{array}{l}\text { O estudo demonstrou que a alimentação interfere } \\
\text { diretamente na qualidade de vida e nos episódios de } \\
\text { depressão, estando correlacionado com a disbiose. }\end{array}$ \\
\hline
\end{tabular}




\begin{tabular}{|c|c|c|c|c|}
\hline $\begin{array}{l}\text { ROGERS et al., } \\
2016\end{array}$ & $\begin{array}{l}\text { From boweldys biosisto } \\
\text { altered brain function } \\
\text { and mental illness: } \\
\text { mechanisms and path } \\
\text { ways }\end{array}$ & $\begin{array}{l}\text { Analisar se asinterações com o eixo } \\
\text { intestino-cérebro, o sistema de } \\
\text { comunicação bidirecional entre o } \\
\text { sistema nervoso central e o trato } \\
\text { gastrointestinal e o microbioma } \\
\text { intestinal também podem } \\
\text { influenciar o desenvolvimento } \\
\text { neural, cognição e comportamental } \\
\text { do individuo. }\end{array}$ & & $\begin{array}{l}\text { O estudo evidenciou que a interação entre o eixo } \\
\text { intestino-cérebro, o sistema de comunicação } \\
\text { bidirecional entre o sistema nervoso central e o trato } \\
\text { gastrointestinal e o microbioma intestinal influenciam } \\
\text { o desenvolvimento neural, comportamento, assim as } \\
\text { modificações no microbioma podem induzir } \\
\text { comportamentos do tipo depressivo. }\end{array}$ \\
\hline $\begin{array}{l}\text { SLYEPCHENKO } \\
\text { et al., } 2016\end{array}$ & $\begin{array}{l}\text { Intestinal Dysbiosis, Gut } \\
\text { Hyperpermeability and } \\
\text { Bacterial Translocation: } \\
\text { Missing Links Between } \\
\text { Depression, Obesity and } \\
\text { Type2 Diabetes }\end{array}$ & $\begin{array}{l}\text { Analisar a correlação entre } \\
\text { distúrbios metabólicos associados } \\
\text { e a depressão }\end{array}$ & $\begin{array}{l}\text { Estudo } \\
\text { Transversal }\end{array}$ & $\begin{array}{l}\text { Há uma correlação entre a depressão e a disbiose, } \\
\text { principalmente entre doenças metabólicas como } \\
\text { Diabetes e Obesidade. Assim os fatores biológicos e } \\
\text { sociais se correlacionam e contribuem para quadros } \\
\text { de depressão. }\end{array}$ \\
\hline SENRA, 2017 & $\begin{array}{l}\text { Alimentação } \\
\text { Depressão }\end{array}$ & $\begin{array}{l}\text { Realizar uma correlação entre } \\
\text { alimentação com a depressão }\end{array}$ & $\begin{array}{l}\text { Estudo } \\
\text { coorte }\end{array}$ & $\begin{array}{l}\text { Os estudos permitiram observar apenas, que os } \\
\text { hábitos alimentares presentes em indivíduos com } \\
\text { depressão, não foi possível evidenciar se os sintomas } \\
\text { depressivos precederam as alterações alimentares ou } \\
\text { se, pelo contrário, os hábitos alimentares precederam } \\
\text { a doença. }\end{array}$ \\
\hline
\end{tabular}




\begin{tabular}{|c|c|c|c|}
\hline SILVA, 2017 & $\begin{array}{l}\text { microbioma } \\
\text { gastrintestinal e a saúde } \\
\text { mental }\end{array}$ & $\begin{array}{l}\text { Explorar o papel do microbioma } \\
\text { gastrointestinal na comunicação } \\
\text { entre o cérebro e o trato } \\
\text { gastrointestinal, bem como no } \\
\text { desenvolvimento de distúrbios do } \\
\text { foro psicológico e neuro- } \\
\text { degenerativo. }\end{array}$ & $\begin{array}{l}\text { O estudo evidenciou que o estilo de vida ocidental } \\
\text { tem contribuído para a modificação da } \\
\text { microbiota gastrointestinal, originando desequilíbrios } \\
\text { no microbioma gastrointestinal (disbiose), o que põe } \\
\text { em risco a integridade da barreira epitelial do } \\
\text { intestino }\end{array}$ \\
\hline $\begin{array}{l}\text { GARCIA; } \\
\text { BUSNELLO } \\
2017\end{array}$ & $\begin{array}{l}\text { A depressão e o não } \\
\text { comer: Revisão de } \\
\text { literatura a partir de } \\
\text { experiência em estágio }\end{array}$ & $\begin{array}{l}\text { Pontuar as relações que existem } \\
\text { entre a depressão e o processo do } \\
\text { não comer, por meio de uma } \\
\text { revisão de literatura. }\end{array}$ & $\begin{array}{l}\text { O estudo evidenciou, que a melhoria das condições } \\
\text { nutricionais da pessoa favorece a autonomia da } \\
\text { alimentação e a recuperação do seu estado } \\
\text { nutricional, que influencia na melhora da depressão. }\end{array}$ \\
\hline $\begin{array}{l}\text { GOMES et al., } \\
2018\end{array}$ & $\begin{array}{l}\text { The influence of } \\
\text { nutritional status in } \\
\text { depression in patients in } \\
\text { palliative care }\end{array}$ & $\begin{array}{l}\text { Analisar a influência do estado } \text { Estudo } \\
\text { nutricional na depressão em Transversal } \\
\text { doentes em cuidados paliativos }\end{array}$ & $\begin{array}{l}\text { O risco do estado nutricional não tem influência na } \\
\text { depressão, observando-se uma associação muito } \\
\text { baixa e positiva ( } r=0.035 ; p=0.817 \text { ), não existindo } \\
\text { diferenças estatisticamente significativas. }\end{array}$ \\
\hline $\begin{array}{l}\text { SZCZESNIAKET } \\
\text { al.,2018 }\end{array}$ & $\begin{array}{l}\text { Isovaleric acids tool } \\
\text { correlates with human } \\
\text { depression }\end{array}$ & $\begin{array}{l}\text { Correlacionar depressão humana Estudo } \\
\text { com disbiose e os ácidos graxos transversal } \\
\text { insaturados }\end{array}$ & 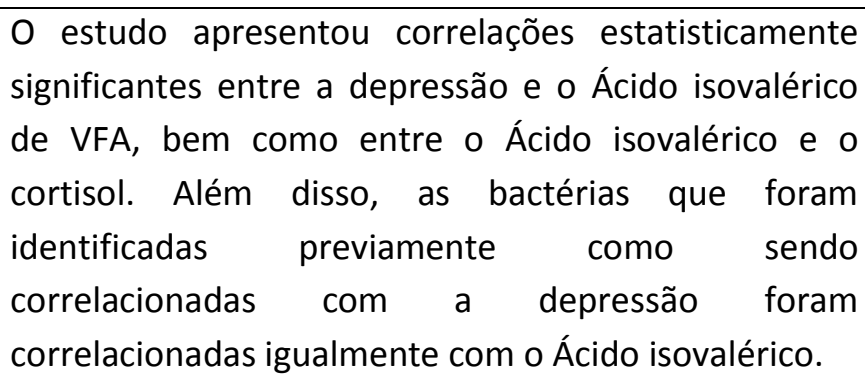 \\
\hline
\end{tabular}




\begin{tabular}{|c|c|c|c|c|}
\hline $\begin{array}{l}\text { GRASES et al., } \\
2019\end{array}$ & $\begin{array}{l}\text { Possiblerelationbetwee } \\
\text { nconsumptionofdifferen } \\
\text { tfoodgroupsanddepressi } \\
\text { on }\end{array}$ & $\begin{array}{l}\text { Avaliar a relação de consumo de } \\
\text { consumo de diferentes grupos } \\
\text { alimentares com depressão. }\end{array}$ & & $\begin{array}{l}\text { Os indivíduos deprimidos consumiram quantidades } \\
\text { significativamente menores de leguminosas, frutas e } \\
\text { vegetais e maiores quantidades de doces e açúcares } \\
\text { refinados. O que há uma associação direta com a } \\
\text { depressão e adisbiose. }\end{array}$ \\
\hline QU et al., 2019 & $\begin{array}{l}\text { Impact of traditional Chi } \\
\text { nese medicine treatmen } \\
\text { t on chronic unpredicta } \\
\text { ble mild stress- } \\
\text { induced depression- } \\
\text { like behaviors: intestinal } \\
\text { microbiota andgut micr } \\
\text { obiome function }\end{array}$ & $\begin{array}{l}\text { Analisar o impacto que } \circ \\
\text { tratamento tradicional da medicina } \\
\text { chinesa tem sobre a disbiose e a } \\
\text { depressão da microbiota intestinal }\end{array}$ & $\begin{array}{l}\text { Estudo } \\
\text { controlado e } \\
\text { randomizado }\end{array}$ & $\begin{array}{l}\text { O estudo demonstrou que a microbiota intestinal tem } \\
\text { papéis importantes na saúde mental das pessoas e } \\
\text { efeito antidepressivo do tratamento tradicionalda } \\
\text { medicina chinesa é relevante para a microbiota } \\
\text { intestinal. }\end{array}$ \\
\hline
\end{tabular}

Fonte: Dados da pesquisa, 2019. 
A fim de uma maior compreensão sobre a importância dos alimentos para a saúde global dos indivíduos, procurou apresentar uma tabela síntese com os alimentos mais indicados ao controle e tratamento da depressão e dos distúrbios alimentares, por entender que uma alimentação saudável e balanceada contribui para diminuição de doenças crônicas, assim como para a longevidade e qualidade de vida.

Tabela 4:Distribuição de alimentos que combatem a depressão e alimentos que ajudam a desencadear a depressão e seus nutrientes.

\begin{tabular}{|c|c|c|c|}
\hline $\begin{array}{c}\text { Alimentos } \\
\text { que } \\
\text { combatem a } \\
\text { depressão }\end{array}$ & Nutrientes & $\begin{array}{l}\text { Alimentos que } \\
\text { ajudam a } \\
\text { depressão }\end{array}$ & Nutrientes \\
\hline Fígado & $\begin{array}{l}\text { Ferro, ácido fólico, } \\
\text { vitaminas B1, B2, B6 e } \\
\text { B12 }\end{array}$ & Chá preto & $\begin{array}{l}\text { Sódio, potássio, carboidratos } \\
\text { e cafeína. }\end{array}$ \\
\hline $\begin{array}{l}\text { Leite } \\
\text { derivados }\end{array}$ & $\begin{array}{l}\text { Cálcio, triptofano, } \\
\text { ferro e Vitamina B12. }\end{array}$ & Café & $\begin{array}{l}\text { Cafeína, sódio, potássio, } \\
\text { cálcio, magnésio, manganês, } \\
\text { fósforo e cobre. }\end{array}$ \\
\hline Peixe & $\begin{array}{l}\text { Triptofano, zinco, } \\
\text { vitaminas B1, B2 e B6. }\end{array}$ & Refrigerantes & Carboidrato e sódio. \\
\hline Banana & $\begin{array}{l}\text { Vitamina } \\
\text { triptofano e ácido } \\
\text { fólico. }\end{array}$ & Doces & Carboidrato e sódio. \\
\hline $\begin{array}{l}\text { Castanha } \\
\text { nozes }\end{array}$ & $\begin{array}{l}\text { Vitamina } E \text {, magnésio, } \\
\text { selênio e zinco }\end{array}$ & $\begin{array}{l}\text { Biscoitos } \\
\text { recheados }\end{array}$ & $\begin{array}{l}\text { Saturados, monoinsaturados } \\
\text { e poli-insaturados. }\end{array}$ \\
\hline Laranja & $\begin{array}{l}\text { Ácido fólico e vitamina } \\
\text { C. }\end{array}$ & Carne vermelha & $\begin{array}{l}\text { Proteína, lipídeos, colesterol, } \\
\text { cálcio, magnésio, fósforo e } \\
\text { ferro. }\end{array}$ \\
\hline Brócolis & $\begin{array}{l}\text { Vitamina E, cálcio, } \\
\text { ferro e ácido fólico. }\end{array}$ & Bebidas alcoólicas & Carboidrato, sódio e álcool \\
\hline Ovos & $\begin{array}{l}\text { Ferro, ácido fólico, } \\
\text { vitaminas B1 e B6. }\end{array}$ & $\begin{array}{l}\text { Salgadinhos } \\
\text { (coxinhas, } \\
\text { pastéis) }\end{array}$ & $\begin{array}{l}\text { Colesterol, lipídeos, } \\
\text { carboidratos e sódio. }\end{array}$ \\
\hline
\end{tabular}




\begin{tabular}{ll}
\hline $\begin{array}{l}\text { Folhas } \\
\text { verde-escuras }\end{array}$ & $\begin{array}{l}\text { Vitaminas } A, C \text { e } E, \\
\text { cálcio, ácido fólico e } \\
\text { zinco. }\end{array}$ \\
\hline Amendoim & $\begin{array}{l}\text { Magnésio e vitamina } \\
\text { B6. }\end{array}$ \\
\hline Feijão & Triptofano e ferro. \\
\hline \multirow{2}{*}{ Aveia } & Cálcio, ferro, \\
& magnésio, vitamina $E$ \\
& e zinco.
\end{tabular}

Fonte: GRASES etal,2019.

\section{DISCUSSÃO}

Nos estudos analisados pode-se perceber que há uma correlação entre disbiose e depressão, em que a escolha de nutrientes adequados para a alimentação diária das pessoas faz a diferença em sua qualidade de vida. De modo que, o envolvimento entre nutrientes e a depressão tem um papel fundamental na gênese da depressão.

Nesse sentido, observou-se nos estudos de Sezini et al., (2014), que o tratamento e acompanhamento nutricional deveria integrar a terapia de todos os pacientes deprimidos, uma vez que, minimizariam os efeitos colaterais e proporcionaria ainda uma melhora física, emocional e psicológica na saúde do indivíduo.

Corroborando esses achados, Veodato et al., (2014) realizou um estudo aprofundado sobre o eixo intestino- cérebro, em que a serotonina apresenta-se como um importante neurotransmissor envolvido na interação entre disbiose, depressão e nutrição, sendo essa neurotransmissor de grande relevância no trato gastrointestinal. Segundo esses autores, tal hormônio acomete a sensação de motilidade e secreção intestinal e também atua na ativação e condução da informação ao sistema nervoso central. Uma diminuição na absorção de nutrientes pode dificultar a síntese e disponibilidade de serotonina, podendo levar a quadros depressivos. 
Observa-se da análise desses dois autores, que a ingestão de bons nutrientes, assim como o tratamento nutricional deveria integrar a terapia de todos os pacientes deprimidos, pois, além de ser livre de efeitos colaterais, também propicia uma melhora global na saúde do indivíduo.

Outro estudo que também evidencia a importância da nutrição no eixo intestino-cérebro é Rodrigues (2015) que evidenciou a influência da disbiose em algumas doenças mentais, especialmente, a depressão. Assim, esse achado afirma que as alterações nas interações cérebro-intestino estão associadas com a inflamação do intestino, síndromes de dor abdominal crônica e transtornos alimentares. Compreende-se, portanto que a modulação da função do eixo cérebro-intestino está associada a alterações específicas na resposta ao estresse e comportamento global.

Já nos estudos Senra (2017) demonstraram que há uma relação bidirecional entre a alimentação e a depressão, em que alguns nutrimentos desempenham um papel importante na qualidade de vida e saúde das pessoas. Assim, esse estudo evidenciou que, determinados padrões alimentares podem estar implicados no desenvolvimento e prevenção da depressão, assim como os resultados de alguns estudos que descrevem a influência que os sintomas depressivos podem ter nos hábitos alimentares e noutros comportamentos relacionados com o estilo de vida.

Nesse sentido, análise dos estudos de Senra (2017), com os de Rodrigues (2015) e Veodato et al., (2014) ressaltam a importância da utilização de suplementos alimentares para a possível melhoria dos sintomas de disbiose e depressão, de modo que se pode afirmar que tais estudos se mostram importantes ao revelar que a composição da microbiota humana é afetada por estados de estresse emocional, assim como os seus metabolitos também podem induzir estados de estresse., 2017).

Achados semelhantes, podem ser observados ao fazer uma análise minuciosa dos estudos de Furtado et al., (2018) e de Gomes et al., (2018) que observaram que a presença de probióticos e prebióticos na alimentação contribuem para a manutenção da composição da microbiota intestinal, produzindo efeitos benéficos. Desse modo, esses componentes nutricionais auxiliam no tratamento da disbiose, contribuindo para uma microbiota intestinal mais saudável.

Embora, esse assunto seja de grande relevância para a sociedade, verificou-se que há poucos estudos relacionadosà depressão e a disbiose, principalmente no que se 
diz respeito à relação disbiose com a presença de transtorno depressivo. Os estudos já realizados permitem a obtenção de informações relevantes quanto à contribuição da microbiota intestinal para o equilíbrio do organismo como um todo, não apenas para o processo digestório como se acreditava anteriormente.

Nesse sentido, há na literatura a sugestão do uso deprobióticos para modulação de sintomas gastrintestinais e psíquicos. De modo, que esse assunto não tem a prentensão de se esgotar aqui, ao contrário, espera-se quem sabe numa Pósgraduação, novas descobertas sobre o papel da dieta na síntese de serotonina, facilitando o tratamento para indivíduos com quadros depressivos.

\section{CONCLUSÃO}

A ciência vem mostrando claramente que o intestino é um dos melhores indicadores com que se pode contar para avaliar a saúde de um indivíduo. Cuidando melhor do sistema gastrintestinal, dessa forma, a aquisição de hábitos de vida saudável, que inclui alimentação com alimentos in natura, frutas, verdades e legumes que são fontes de fibras e alimentos com probióticos, mostra-se como estratégia promissora á saúde e ao bem-estar físico e emocional. Conclui-se a necessidade de novos estudos, novas investigações, que serão indispensáveis e essenciais para compreender melhor o mundo da microbiota intestinal e suas inter-relações. Com a significativa relação existente entre o intestino e o cérebro, torna-se essencial o papel do profissional de Nutrição juntamente com uma equipe multiprofissional, não só para tratar e melhorar sintomas da disbiose, mas também no tratamento de depressão.

\section{REFERÊNCIAS}

CONRADO, B. Á.; SOUZA, S. A. Disbiose Intestinal em idosos e aplicabilidade dos probióticos e prebióticos, Cadernos UniFOA. Edição 36, abril de 2018.

FURTADO, Celine de carvalho et al, Psicobióticos: Uma ferramenta para o tratamento no transtorno da ansiedade e depressão?Revista UNILUS Ensino e Pesquisa v. 15, n. 40, jul./set. 2018. 
GARCIA, Maria Cristina Roppa, BUSNELLO, Maristela Borin, A Depressão e o não comer: Revisão de literatura a partir de experiência em estágio, Evento: XVIII Jornada de Extensão, UNIJUÍ, 2017.

GRASES etal, Possível relação entre consumo de diferentes grupos alimentares e depressão, BMC Psicologia, 2019.

GOMES, A. M. S. et al. The influence of nutritional status in depression in patients in palliative care. Millenium, v. 46, n. 23,jan./jun. P. 137-149, 2018.

PEREIRA, M. L. A. et al. Relação Da Disbiose Intestinal Na Depressão: Revisão Integrativa. FJN, n. 12, n. 4, p. 34-45, 2018.

REIS, M. A.; MELO, A. K.,A depressão do mundo vivido.XXI Encontro de Iniciação à Pesquisa Universidade de Fortaleza, 2015.

RODRIGUES, Thaís Pereira, Possível relação entre microbiota intestinal e depressão em humanos: Uma revisão de literatura. Universidade Católica de Brasília- DF, 2015.

SENRA, Inês do Carmo Ribeiro, Alimentação e Depressão, Faculdade de Ciências da Nutrição e Alimentação da Universidade do Porto , 2017.

SEZINI, A. M.; GIL, C. S. G., Nutrientes e depressão. Vita et Sanitas, Trindade-GO,n.08, 2014.

SLYEPCHENKO, A.et al.,Intestinal Dysbiosis, Gut Hyperpermeability and Bacterial Translocation: Missing Links Between Depression, Obesity and Type 2 Diabetes. CurrPharm Des., v.22, n.40, p.6087-6106, 2016.

SILVA, I. CRISTÓVÃO,A. F. O microbioma gastrointestinal e a saúde mental. Faculdade do Porto, 2017.

SOUZA, J. P.; BRETEGANI, L. M. The influence of alimentation about the intestinal microbiota and immunity..Cad. Naturol. Terap., São Paulo, v. 5, n. p. 47-53, 2016.

SZCZESNIAKET, O. et al. Isovalericacids tool correlates with human depression. NutrNeurosci; v.19, n. 7, p. 279-83, set. 2018.

VEDOVATO, et al $O$ eixo intestino-cérebro e o papel da serotonina. Arq.Ciênc.SaúdeUnipar, Umuarama, v. 18 n. 1, p. 33-42, 2014. 